\title{
sciendo
}

\section{Effects of Dual Task Interference on Biomechanics of the Entire Lower Extremity During the Drop Vertical Jump}

\author{
by \\ Satoshi Imai ${ }^{1}$ Kengo Harato ${ }^{1,2}$, Yutaro Morishige2, Shu Kobayashi², Yasuo Niki², \\ Kazuki Sato ${ }^{1}$, Takeo Nagura ${ }^{2,3}$
}

\begin{abstract}
The dual task is an important factor affecting knee biomechanics during jump-landing tasks. Athletes often have trouble in performing two tasks concurrently and a dual task can deteriorate landing performance. However, it is still unknown whether a dual task will affect the entire lower extremity. The purpose of this study was to clarify the effects of cognitive task interference on biomechanics of hip and ankle joints as well as the knee joint during the drop vertical jump (DVJ). A total of 20 female collegiate athletes participated in the study. Athletes performed a DVJ with or without a cognitive task. The DVJ was captured using a motion analysis system. Mental arithmetic of 2-digit addition was used as a cognitive task. Maximum vertical ground reaction force (vGRF), joint angles at initial contact (IC), joint moments within 40 milliseconds (ms) after IC, and joint angles and moments at peak vGRF were assessed. The data were statistically compared between with and without a cognitive task condition using a two-tailed paired $t$-test or the Wilcoxon singed rank test. The peak external knee abduction moment on both limbs within 40 ms after IC during the DVJ was significantly larger in the dual task than in the single task with less knee and hip flexion at initial contact. In addition, all moments of hip and ankle joints within $40 \mathrm{~ms}$ after IC were significantly larger in the dual task than in the single task accompanied with greater $v G R F$, except for the hip internal rotation moment. Cognitive tasks during a DVJ will result in biomechanical changes of the entire lower extremity in female athletes.
\end{abstract}

Key words: cognitive task, landing biomechanics, motion capture system, female athletes.

\section{Introduction}

Anterior cruciate ligament (ACL) injury is one of the major sport injuries in youth athletes. This can be a devastating sport trauma as the surgical procedure is usually done for those athletes and postoperative careful rehabilitation is necessary for a long period of time. Therefore, mechanisms of ACL injury should be revealed for prevention. Generally, 70\% of ACL injury at the knee joint occur during non-contact episodes such as deceleration, lateral pivoting and landing tasks (Arendt and Dick, 1995; David et al., 2017; Griffin et al., 2000). So far, many studies have been conducted to understand the ACL loading and injury mechanism using various techniques including motion capture and imaging technologies. For example, the model-based image-matching method showed that rapid valgus and internal rotational development immediately after initial contact (IC) was related to non-contact ACL injury (Koga et al., 2010). Moreover, in terms of a biomechanical study, female athletes with an increased knee valgus angle at IC, a peak knee valgus angle, and a peak knee abduction moment would be associated with an increased risk of non-contact ACL injury during landing tasks (Hewett and Myer, 2011; Hewett et al., 2005, 2009). Clinically, the Drop Vertical Jump (DVJ) evaluated using the motion capture system has been used to assess the risk

1 - Institute for Integrated Sports Medicine, Keio University School of Medicine, Tokyo, Japan.

2 - Department of Orthopedic Surgery, Keio University School of Medicine, Tokyo, Japan.

3 - Department of Clinical Biomechanics, Keio University School of Medicine, Tokyo, Japan. 
factor in non-contact ACL injury in female athletes (Padua et al., 2015). Since in the literature the focus has usually been laid on the DVJ in experiments for evaluation of the risk factor, a conventional laboratory-based DVJ may be a single-task. Although athletes always perform these movement with a dual- or a multi-task such as estimating the surrounding situations and making another purposeful movement in the actual sport field, few reports have been done to assess the influence of a dual task on knee biomechanics. According to previous reports, people often have trouble performing two tasks concurrently (Pashler, 1994), and a dual-task might deteriorate landing performance (Dai et al., 2018). Furthermore, a recent review paper demonstrated that decision making and divided attention would affect knee biomechanics associated with ACL injury (Hughes and Dai, 2021). For instance, decision making could significantly influence several biomechanical variables related to an increased risk of ACL injury, such as reduced knee flexion at initial contact, increased knee valgus angles, increased knee extension and valgus moments (Hughes and Dai, 2021). In terms of correlation between trunk motion and ACL injuries, limited trunk flexion and increased trunk lateral bending were associated with increased ACL loading (Song et al., 2021). However, little attention has been paid to the effects of cognitive task interference on biomechanics of the entire lower extremity during sporting activity.

Therefore, the purpose of the present study was to examine and clarify the effects of cognitive task (dual task) interference on biomechanics of the entire lower extremity during jump-landing tasks. It was hypothesized that cognitive task interference would lead to deterioration of biomechanics of the entire lower extremity during the DVJ.

\section{Methods}

\section{Participants}

A total of 20 female collegiate athletes (mean age $=20.2 \pm 1.3$ years) participated in the present study. All participants were members of college sports teams (basketball: 9, volleyball: 4, ski: 4, badminton: 3 ) and their average practice time was longer than 18 hours a week. The average of sporting experience was $6.4 \pm 3.6$ years, and the Tegner activity level scale was 7 for each subject. The present study was conducted in the Sports Rehabilitation and Performance Laboratory and approved by the Medical Research Ethics Committee of our university ( $\$ 20080054)$. Each participant provided a written informed consent form. None of the athletes had any history of major injuries of the trunk or lower extremities. In the current investigation, female athletes were recruited, since females present a greater risk of ACL injury than males based on previous studies (Ford et al., 2010; Gornitzky et al., 2016; Krosshaug et al., 2007).

\section{DVJ protocol and data analysis}

The jump-landing biomechanics during the Drop Vertical Jump (DVJ) were examined (Hewett and Myer, 2011; Hewett et al., 2005). Participants were asked to perform a DVJ from a $30 \mathrm{~cm}$ high box forward to a distance of $25 \%$ of their height away from the box, and immediately jump vertically as high as possible. After the instruction and practice of the DVJ, participants performed three conventional DVJ trials (a singletask). After single-task DVJs, a three-minute rest was allowed. Then, athletes performed two DVJ trials with a cognitive task (a dual task), which included the mental arithmetic of 2-digit addition. This calculation was given on the screen just before the DVJ by an examiner. Thereafter each participant thought about the answer as accurately as possible and gave the solution to the examiner after the DVJ. The range of the starting number for the addition was 50 to 99 . The mental arithmetic of 2-digit addition was chosen in the present study as an easier method was applied compared to 2-digit subtraction. Before DVJ trials, the correct answer was given by $50.0 \%$ of athletes for 2-digit addition, while only $33.3 \%$ of athletes responded correctly to 2-digit subtraction.

Lower limb kinematics and kinetics data were recorded using a three-dimensional motion analysis system which consisted of eight cameras (120 frames/s; Oqus, Qualisys, Sweden), two force plates (frequency $600 \mathrm{~Hz}$; AM6110, Bertec, Columbus, OH, USA), and 46 retro-reflective markers (14 $\mathrm{mm}$ in diameter). Those markers were placed on anatomic landmarks and specific locations (Harato et al., 2019; Kadaba et al., 1990; Morishige et al., 2010; Sakurai et al., 2019a, 2019b). A set of anatomical landmarks were defined as follows: the spinous process of vertebrae at the 
level of $C 7$ and Th 10, the jugular notch and xiphoid process of the sternum, acromion, anterior superior and posterior superior iliac spine, greater trochanter, medial and lateral femoral epicondyles, medial and lateral malleoli, the head of the first and the fifth metatarsal bone, scaphoid, and calcaneus. Additional specific markers were placed on the frontal and lateral aspects of the thigh (4 markers) and the shank (4 markers). The set of markers was used to calculate joint centers and segment positions in a standard quiet stance, and to track segment motion during the DVJ tests. Joint angles were calculated based on the cardan sequence of $\mathrm{XYZ}$, equivalent to the joint coordinate system. Joint moments were calculated using inverse dynamics within commercial software (C-motion Company, Rockville, MD, USA), then normalized to mass (kilograms) and calculated as external moments.

The following data were evaluated with reference to previous studies (Cochrane et al., 2007; Hewett et al., 2005; Koga et al., 2010; Krosshaug et al., 2007; Leppanen et al., 2017): 1) jumping height as a value of motor performance, 2) maximum vertical ground reaction force (vGRF), 3) joint angles at initial contact (IC), 4) joint moments within $40 \mathrm{~ms}$ after IC, and 5) joint angles and moments at peak vGRF. The jumping height was calculated by the maximum height of Th10. The outline of these values is shown in Figure 1. These evaluations were done for both limbs including dominant and non-dominant legs. The dominant leg was defined as the leg with which each athlete preferred to kick a ball (Brophy et al., 2010; Negrete et al., 2007). A lowpass filter was used to smooth marker and GRF data at the cutoff frequency of $12 \mathrm{~Hz}$.

\section{Statistical analysis}

Biomechanical differences were analyzed between a single- and a dual-task during jump-landing movement. To analyze the differences, the effect size, statistical significance and power were set at $d=0.8, \alpha=0.05, \beta=0.95$, respectively. A power analysis was performed using G*Power (v3.1.9.2, Heinrich-Heine University, Düsseldorf, Germany). Using a large effect size of 0.6 for a two-tailed $t$-test, a sample size of 17 was required in each group $(\beta=0.80, \alpha=$ $0.05)$. To clarify the effects of the dual task on lower limb biomechanics, the values of lower limb kinematics and kinetics under single task condition were used as controls. The two-tailed paired $t$-test or the Wilcoxon singed rank test was performed between with and without a cognitive task condition after confirming the normality assumption using the Shapiro-wilk test. Statistical significance was set at $p<0.05$. All statistical analyses were performed using SPSS (ver. 22, IBM Corporation, Armonk, NY, USA.).

\section{Results}

\section{Peak vGRF during landing phase and joint angles at initial contact}

The right-side limb was judged as dominant for 19 participants. In terms of jumping performance, no significant difference was found between a single and a dual task (single-task: 33.4 $\pm 6.4 \mathrm{~cm}$, dual-task: $31.5 \pm 5.3 \mathrm{~cm}$ ). On the other hand, significant differences were found in peak vGRF during the landing phase. Specifically, total vGRF was significantly larger in the dual task than in the single task (Figure 2). Furthermore, significant increases were found in the nondominant leg (single task: $22.1 \pm 6.2 \mathrm{~N} / \mathrm{kg}$, dualtask: $26.6 \pm 8.9 \mathrm{~N} / \mathrm{kg}$ ), while no significant difference was detected in the dominant leg.

Although knee abduction and internal rotation angles were not significantly different, other variables including knee flexion, hip flexion, and ankle planter-flexion angles at IC were significantly smaller in the dual task than in the single task on both limbs (Table 1).

\section{Joint moments within $40 \mathrm{~ms}$ after initial contact}

The peak external knee abduction moment in the dominant leg within $40 \mathrm{~ms}$ after initial contact was significantly larger in the dual task than in the single task (Table 2).

As to the non-dominant leg, knee flexion and internal rotation moments were significantly larger in the dual task than in the single task as well as the knee abduction moment. In terms of hip and ankle joints, most of the moments were significantly larger in the dual task than in the single task, whereas no significant difference was detected in the hip internal rotation moment.

Joint angles and moments at the timing of peak vGRF

Hip and knee flexion angles were significantly smaller in the dual task than in the single task (Table 3) on dominant and nondominant sides. Regarding the knee abduction angle, there were no significant differences 
between single and dual tasks in both limbs.

Concerning joint moments, almost all of the moments were not significantly different between single and dual tasks, while the knee abduction moment in the dominant leg and the knee flexion moment in the non-dominant leg were larger in the dual task than in the single task (Table 4).

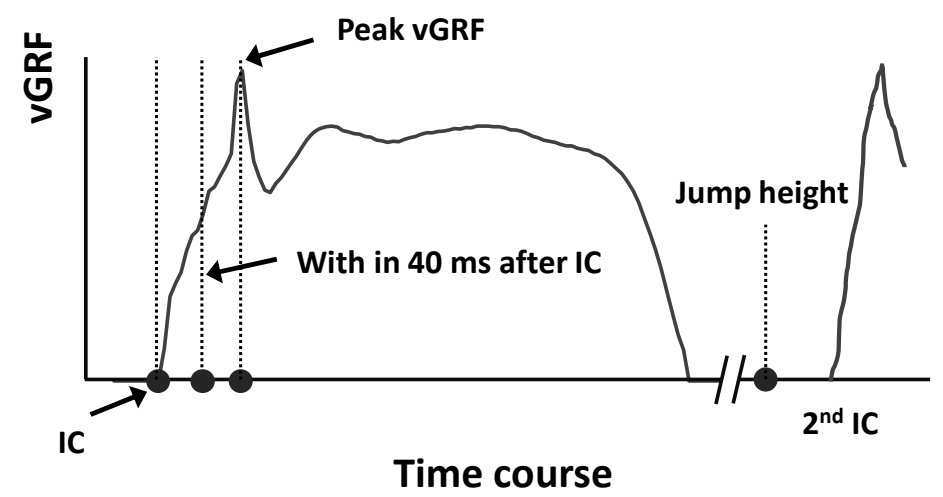

\section{Figure 1}

vGRF-time curve during DVJ.IC: initial contact, vGRF: vertical ground reaction force

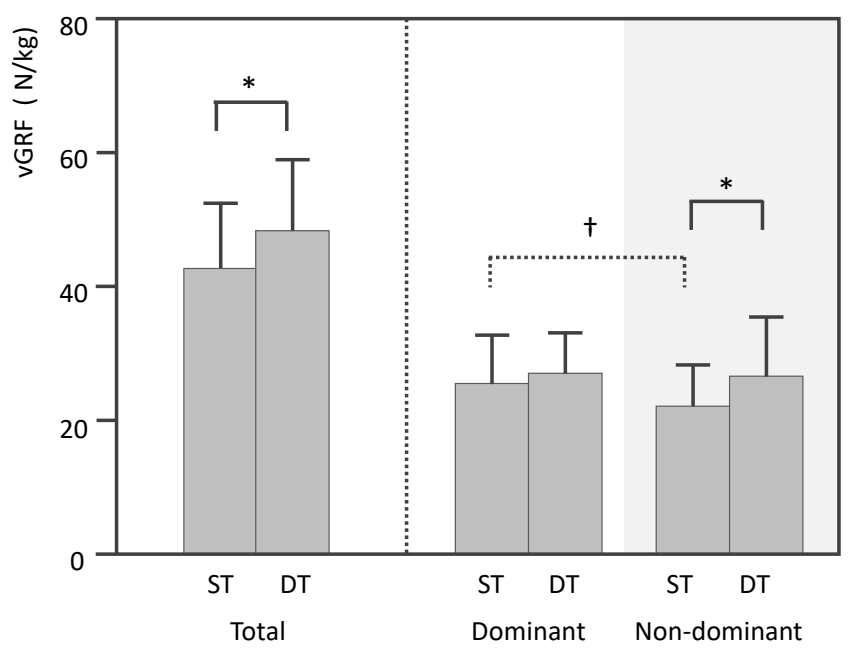

Figure 2

$v G R F$ under the dominant and the non-dominant foot, and the both feet (total) during the DVJ in the ST and DT conditions.vGRF: vertical ground reaction force, ST: single-

task, DT: dual-task.*: significant difference between ST and DT. +: significant difference between dominant and non-dominant 
Table 1

Angles of the hip, knee and ankle at initial contact (degrees, mean $\pm S D$ ).

\begin{tabular}{|c|c|c|c|c|}
\hline & & Single Task & Dual Task & $p$ value $^{a}$ \\
\hline \multicolumn{5}{|c|}{ Dominant side } \\
\hline \multirow[t]{3}{*}{ Hip } & Flexion & $21.0 \pm 7.7$ & $18.8 \pm 8.0$ & 0.035 \\
\hline & Abduction & $4.3 \pm 3.3$ & $4.2 \pm 2.9$ & 0.906 \\
\hline & Internal rot & $-0.8 \pm 8.2$ & $-0.7 \pm 8.0$ & 0.971 \\
\hline \multirow[t]{3}{*}{ Knee } & Flexion & $22.5 \pm 5.6$ & $19.7 \pm 5.6$ & 0.027 \\
\hline & Abduction & $-0.8 \pm 3.3$ & $-0.9 \pm 3.8$ & 0.763 \\
\hline & Internal rot & $-10.9 \pm 8.9$ & $-12.1 \pm 7.5$ & 0.296 \\
\hline \multirow[t]{3}{*}{ Ankle } & Plantar Flex & $22.7 \pm 4.8$ & $25.6 \pm 4.3$ & 0.002 \\
\hline & Abduction & $-13.0 \pm 4.8$ & $-12.1 \pm 5.1$ & 0.189 \\
\hline & Internal rot & $1.7 \pm 6.2$ & $1.8 \pm 6.2$ & 0.943 \\
\hline \multicolumn{5}{|c|}{ Non-Dominant side } \\
\hline \multirow[t]{3}{*}{ Hip } & Flexion & $23.0 \pm 7.4$ & $20.7 \pm 6.5$ & 0.026 \\
\hline & Abduction & $5.7 \pm 4.6$ & $5.7 \pm 4.8$ & 0.931 \\
\hline & Internal rot & $3.9 \pm 7.2$ & $3.9 \pm 7.3$ & 0.845 \\
\hline \multirow[t]{3}{*}{ Knee } & Flexion & $26.8 \pm 6.2$ & $24.2 \pm 6.0$ & 0.070 \\
\hline & Abduction & $-2.6 \pm 3.8$ & $-2.3 \pm 3.7$ & 0.611 \\
\hline & Internal rot & $-9.7 \pm 7.2$ & $-10.5 \pm 8.7$ & 0.374 \\
\hline \multirow[t]{3}{*}{ Ankle } & Plantar Flex & $19.0 \pm 5.0$ & $22.1 \pm 5.6$ & 0.001 \\
\hline & Abduction & $-13.1 \pm 7.0$ & $-13.3 \pm 6.0$ & 0.741 \\
\hline & Internal rot & $-0.7 \pm 6.8$ & $0.4 \pm 8.0$ & 0.126 \\
\hline
\end{tabular}

a Values obtained using a two-tailed paired $t$-test or the Wilcoxon singed rank test

Table 2

Peak external knee abduction moments of the hip, knee and ankle within 40 ms after initial contact ( $\mathrm{Nm} / \mathrm{kg}$, mean $\pm \mathrm{SD}$ ).

\begin{tabular}{|c|c|c|c|c|}
\hline & & Single Task & Dual Task & $p$ value \\
\hline \multicolumn{5}{|c|}{ Dominant side } \\
\hline \multirow[t]{3}{*}{ Hip } & Flexion & $2.71 \pm 1.11$ & $3.08 \pm 0.96$ & 0.036 \\
\hline & Adduction & $1.03 \pm 0.33$ & $1.39 \pm 0.50$ & $<0.001$ \\
\hline & Internal rot & $0.38 \pm 0.17$ & $0.46 \pm 0.22$ & 0.077 \\
\hline \multirow[t]{3}{*}{ Knee } & Flexion & $1.44 \pm 0.66$ & $1.62 \pm 0.53$ & 0.251 \\
\hline & Abduction & $0.50 \pm 0.24$ & $0.71 \pm 0.31$ & 0.003 \\
\hline & Internal rot & $0.27 \pm 0.14$ & $0.37 \pm 0.15$ & 0.249 \\
\hline \multirow[t]{3}{*}{ Ankle } & Dorsal flex & $1.04 \pm 0.31$ & $1.17 \pm 0.18$ & 0.031 \\
\hline & Abduction & $0.17 \pm 0.11$ & $0.23 \pm 0.12$ & 0.003 \\
\hline & Internal rot & $0.15 \pm 0.07$ & $0.18 \pm 0.07$ & 0.013 \\
\hline \multicolumn{5}{|c|}{ Non-Dominant side } \\
\hline \multirow[t]{3}{*}{ Hip } & Flexion & $2.23 \pm 0.55$ & $2.63 \pm 0.59$ & 0.024 \\
\hline & Adduction & $1.18 \pm 0.28$ & $1.46 \pm 0.47$ & 0.025 \\
\hline & Internal rot & $0.58 \pm 0.24$ & $0.66 \pm 0.33$ & 0.293 \\
\hline \multirow[t]{3}{*}{ Knee } & Flexion & $1.45 \pm 0.32$ & $1.88 \pm 0.66$ & 0.006 \\
\hline & Abduction & $0.53 \pm 0.22$ & $0.70 \pm 0.25$ & 0.002 \\
\hline & Internal rot & $0.28 \pm 0.09$ & $0.38 \pm 0.12$ & 0.001 \\
\hline \multirow[t]{3}{*}{ Ankle } & Dorsal flex & $0.94 \pm 0.29$ & $1.04 \pm 0.31$ & 0.038 \\
\hline & Abduction & $0.13 \pm 0.10$ & $0.20 \pm 0.11$ & 0.006 \\
\hline & Internal rot & $0.21 \pm 0.11$ & $0.28 \pm 0.10$ & 0.008 \\
\hline
\end{tabular}

${ }^{a}$ Values obtained using a two-tailed paired t-test or the Wilcoxon singed rank test 
Table 3

Angles of the hip, knee and ankle at the timing of peak vertical ground reaction force (degrees, mean $\pm S D$ ).

\begin{tabular}{ccccc}
\hline & & Single Task & Dual Task & $p$ value $^{\mathrm{a}}$ \\
\hline Dominant side & & & & \\
Hip & Flexion & $28.5 \pm 7.8$ & $26.2 \pm 8.3$ & 0.039 \\
& Abduction & $3.0 \pm 3.8$ & $3.2 \pm 3.6$ & 0.719 \\
Knee & Internal rot & $0.1 \pm 8.9$ & $0.6 \pm 8.3$ & 0.410 \\
& Flexion & $44.7 \pm 5.4$ & $41.6 \pm 6.6$ & 0.021 \\
& Abduction & $-1.0 \pm 5.5$ & $-1.7 \pm 5.6$ & 0.221 \\
& Internal rot & $-6.0 \pm 8.2$ & $-7.2 \pm 7.2$ & 0.148 \\
Ankle & Plantar Flex & $10.3 \pm 6.8$ & $9.8 \pm 8.6$ & 0.696 \\
& Abduction & $-6.3 \pm 3.6$ & $-5.9 \pm 2.7$ & 0.540 \\
& Internal rot & $-5.0 \pm 6.2$ & $-4.2 \pm 6.3$ & 0.293 \\
Non-Dominant side & & & \\
Hip & Flexion & $30.1 \pm 7.1$ & $27.6 \pm 8.3$ & 0.020 \\
& Abduction & $5.2 \pm 5.2$ & $5.5 \pm 5.8$ & 0.642 \\
& Internal rot & $4.9 \pm 8.6$ & $4.9 \pm 8.6$ & 0.962 \\
Knee & Flexion & $47.1 \pm 4.9$ & $44.1 \pm 7.2$ & 0.018 \\
& Abduction & $-3.3 \pm 7.2$ & $-3.3 \pm 6.5$ & 0.951 \\
& Internal rot & $-5.0 \pm 7.3$ & $-5.7 \pm 8.9$ & 0.317 \\
Ankle & Plantar Flex & $10.4 \pm 8.4$ & $9.5 \pm 10.1$ & 0.511 \\
& Abduction & $-7.0 \pm 3.9$ & $-7.2 \pm 3.9$ & 0.652 \\
& Internal rot & $-7.2 \pm 6.7$ & $-5.5 \pm 7.3$ & 0.003 \\
\hline
\end{tabular}

a Values obtained using a two-tailed paired t-test or the Wilcoxon singed rank test

Table 4

Joint moments of the hip, knee and ankle at the timing of peak vertical ground reaction force $(\mathrm{Nm} / \mathrm{kg}$, mean $\pm \mathrm{SD})$.

\begin{tabular}{|c|c|c|c|c|}
\hline & & Single Task & Dual Task & $p$ value $^{\mathrm{a}}$ \\
\hline \multicolumn{5}{|c|}{ Dominant side } \\
\hline \multirow[t]{3}{*}{ Hip } & Flexion & $0.03 \pm 1.33$ & $-0.17 \pm 1.54$ & 0.651 \\
\hline & Adduction & $0.03 \pm 0.37$ & $0.14 \pm 0.70$ & 0.370 \\
\hline & Internal rot & $0.02 \pm 0.15$ & $0.03 \pm 0.25$ & 0.344 \\
\hline \multirow[t]{3}{*}{ Knee } & Flexion & $1.04 \pm 0.75$ & $0.99 \pm 0.66$ & 0.791 \\
\hline & Abduction & $-0.07 \pm 0.14$ & $0.08 \pm 0.26$ & 0.005 \\
\hline & Internal rot & $0.00 \pm 0.09$ & $0.02 \pm 0.13$ & 0.362 \\
\hline \multirow[t]{3}{*}{ Ankle } & Dorsal flex & $0.97 \pm 0.30$ & $1.03 \pm 0.21$ & 0.348 \\
\hline & Abduction & $0.07 \pm 0.15$ & $0.06 \pm 0.15$ & 0.788 \\
\hline & Internal rot & $0.02 \pm 0.07$ & $-0.02 \pm 0.10$ & 0.714 \\
\hline \multicolumn{5}{|c|}{ Non-Dominant side } \\
\hline \multirow[t]{3}{*}{ Hip } & Flexion & $0.27 \pm 0.69$ & $0.17 \pm 1.03$ & 0.089 \\
\hline & Adduction & $-0.05 \pm 0.31$ & $-0.02 \pm 0.54$ & 0.788 \\
\hline & Internal rot & $0.00 \pm 0.13$ & $0.02 \pm 0.20$ & 0.039 \\
\hline \multirow[t]{3}{*}{ Knee } & Flexion & $0.84 \pm 0.52$ & $1.12 \pm 0.81$ & 0.025 \\
\hline & Abduction & $-0.05 \pm 0.24$ & $-0.04 \pm 0.31$ & 0.888 \\
\hline & Internal rot & $0.01 \pm 0.09$ & $0.02 \pm 0.14$ & 0.612 \\
\hline \multirow[t]{3}{*}{ Ankle } & Dorsal flex & $0.84 \pm 0.33$ & $0.89 \pm 0.29$ & 0.256 \\
\hline & Abduction & $0.07 \pm 0.12$ & $0.10 \pm 0.14$ & 0.238 \\
\hline & Internal rot & $0.05 \pm 0.10$ & $0.06 \pm 0.09$ & 0.632 \\
\hline
\end{tabular}

a Values obtained using a two-tailed paired $t$-test or the Wilcoxon singed rank test 


\section{Discussion}

The results of the present study partly supported the hypothesis that cognitive task interference would lead to deterioration of leg biomechanics during the DVJ. The most important finding of the current investigation was that the peak external knee abduction moment in both limbs within $40 \mathrm{~ms}$ after initial contact was significantly larger in the dual task than in the single task with less knee and hip flexion at initial contact. In addition, this phenomenon was observed without deterioration of jumping performance in the dual task.

According to a previous study, a lesser knee flexion angle and high abduction loads were important biomechanical risk factors of ACL injury in female athletes (Koga et al., 2010). In terms of the timing of the injury, a non-contact ACL injury mechanism was investigated using video sequences, and the timing of the injury was within $40 \mathrm{~ms}$ after IC. Therefore, knee kinematics and loading within $40 \mathrm{~ms}$ could be a key factor in the ACL injury mechanism. Based on the results of the present study, most of the moments within $40 \mathrm{~ms}$ after IC were significantly larger in dual than in single tasks accompanied with greater vGRF. Besides, less knee and hip flexion at IC in landing tasks was known as stiff landing (Devita and Skelly, 1992; Leppanen et al., 2017). The current study indicated that cognitive task interference would lead to stiff landing, as smaller hip flexion, smaller knee flexion and greater ankle plantar flexion were observed at IC in dual tasks. Similarly, Dai et al. (2018) suggested that introduction of a simultaneous cognitive challenge might result in stiff landing and adversely affect motor programming required for safe execution of jump landings. Furthermore, Almonroeder et al. (2018) demonstrated that the inclusion of the cognitive task such as the overhead goal resulted in higher peak vertical ground reaction forces and lower peak knee flexion angles in comparison to the standard DVJ. However, the focus of their studies was laid on knee biomechanics without assessing hip and ankle joints. Generally, hip and ankle motions will interact with knee biomechanics as a kinetic chain among the entire lower extremity (Koga et al., 2018). For instance, hip adduction and ankle abduction moments as well as internal rotation moments at both joints will affect the knee abduction moment. In the present study, significantly larger hip adduction and ankle abduction/internal rotation moments were observed accompanied with a larger knee abduction moment within $40 \mathrm{~ms}$ after IC for both limbs in dual tasks compared to single tasks, whereas the hip internal rotation moment was not significantly different between the two conditions. Consideration of the entire lower extremity can contribute to a better understanding of ACL injury mechanisms.

A neuromuscular reaction to perturbation is considered to require a longer time than $50 \mathrm{~ms}$. For example, Forgard et al. (2015) reported that fast perturbations applied to the limbs would elicit stereotypical, electromyographic responses in the stretched muscle and the first response would occur at short latency $(25-50 \mathrm{~ms})$ and reflect input from a spinal reflex pathway. This is followed by a longer latency (50-100 ms) response, which receives input from group II afferents travelling a spinal pathway as well as group I afferents traversing a longer transcortical route. Moreover, Moritz and Farley (2004) investigated whether the contribution of anticipation and reaction would change when human hoppers encountered surprising, expected, and random changes from a soft elastic surface to a hard surface. They indicated that the mechanical changes occurred before electromyography changed $68-188 \mathrm{~ms}$ after landing. Therefore, to achieve an appropriate jump performance, a longer time than $50 \mathrm{~ms}$ is required for athletes to react to the unexpected event after the ground contact, and it is necessary to adjust the joint angle and muscle contraction predictively. Thus, stiff landing should be observed as a result of this predictive compensation for perturbation.

Several limitations should be described in the present study. First, the cognitive task in the present study was nothing but a simulation, as a sports specific task is ideal for the investigation. Second, study participants were limited to female athletes of college sports teams with the Tegner activity scale result of 7 including basketball, volleyball, ski and badminton. The characteristics of biomechanics in the DVJ may change based on the type of sport, and the results of the current investigation may not be applicable to all athletes. Third, joint moments in the present study were assessed within $40 \mathrm{~ms}$ after IC and at the timing of 
peak GRF, as wider range greater than $40 \mathrm{~ms}$ would have possibly included the timing of peak GRF. Lastly, electromyography was not utilized in the present study, as a lot of markers were required to minimize skin motion error. Nonetheless, the present results provide important information regarding the effect of cognitive tasks on biomechanical changes of lower limbs during the DVJ in female athletes.

From the present study, we may conclude that dual task condition during the DVJ affects the

\section{Acknowledgements}

The authors gratefully acknowledge the valuable contribution of Hideo Matsumoto, MD, PhD, Toshiro Otani, MD, PhD, Aiko Sakurai, RPT, Mr. Ryoji Hayakawa and Mrs. Sumi Yamashita.

\section{References}

Almonroeder, T. G., Kernozek, T., Cobb, S., Slavens, B., Wang, J., \& Huddleston, W. (2018). Cognitive Demands Influence Lower Extremity Mechanics During a Drop Vertical Jump Task in Female Athletes. Journal of Orthopaedic and Sports Physical Therapy, 48(5), 381-387. https://doi.org/10.2519/jospt.2018.7739

Arendt, E., \& Dick, R. (1995). Knee injury patterns among men and women in collegiate basketball and soccer. NCAA data and review of literature. American Journal of Sports Medicine, 23(6), 694-701. https://doi.org/10.1177/036354659502300611

Brophy, R., Silvers, H. J., Gonzales, T., \& Mandelbaum, B. R. (2010). Gender influences: the role of leg dominance in ACL injury among soccer players. British Journal of Sports Medicine, 44(10), 694-697. https://doi.org/10.1136/bjsm.2008.051243

Cochrane, J. L., Lloyd, D. G., Buttfield, A., Seward, H., \& McGivern, J. (2007). Characteristics of anterior cruciate ligament injuries in Australian football. Journal of Science and Medicine in Sport, 10(2), 96-104. https://doi.org/10.1016/j.jsams.2006.05.015

Dai, B., Cook, R. F., Meyer, E. A., Sciascia, Y., Hinshaw, T. J., Wang, C., \& Zhu, Q. (2018). The effect of a secondary cognitive task on landing mechanics and jump performance. Sports Biomechanics, 17(2), 192205. https://doi.org/10.1080/14763141.2016.1265579

David, S., Komnik, I., Peters, M., Funken, J., \& Potthast, W. (2017). Identification and risk estimation of movement strategies during cutting maneuvers. Journal of Science and Medicine in Sport, 20(12), 10751080. https://doi.org/10.1016/j.jsams.2017.05.011

Devita, P., \& Skelly, W. A. (1992). Effect of landing stiffness on joint kinetics and energetics in the lower extremity. Medicine $\mathcal{E}$ Science in Sports $\mathcal{E}$ Exercise, 24(1), 108-115. https://www.ncbi.nlm.nih.gov/pubmed/1548984

Ford, K. R., Shapiro, R., Myer, G. D., Van Den Bogert, A. J., \& Hewett, T. E. (2010). Longitudinal sex differences during landing in knee abduction in young athletes. Medicine $\mathcal{E}$ Science in Sports \& Exercise, 42(10), 1923-1931. https://doi.org/10.1249/MSS.0b013e3181dc99b1

Forgaard, C. J., Franks, I. M., Maslovat, D., Chin, L., \& Chua, R. (2015). Voluntary reaction time and longlatency reflex modulation. The Journal of Neurophysiology, 114(6), 3386-3399. https://doi.org/10.1152/jn.00648.2015

Gornitzky, A. L., Lott, A., Yellin, J. L., Fabricant, P. D., Lawrence, J. T., \& Ganley, T. J. (2016). Sport-Specific Yearly Risk and Incidence of Anterior Cruciate Ligament Tears in High School Athletes: A Systematic Review and Meta-analysis. American Journal of Sports Medicine, 44(10), 2716-2723. https://doi.org/10.1177/0363546515617742

Griffin, L. Y., Agel, J., Albohm, M. J., Arendt, E. A., Dick, R. W., Garrett, W. E., . . Wojtys, E. M. (2000). 
Noncontact anterior cruciate ligament injuries: risk factors and prevention strategies. Journal of the $\begin{array}{lllll}\text { American Academy of } & \text { Orthopaedic Surgeons, }\end{array}$ https://www.ncbi.nlm.nih.gov/pubmed/10874221

Harato, K., Sakurai, A., Morishige, Y., Kobayashi, S., Niki, Y., \& Nagura, T. (2019). Biomechanical correlation at the knee joint between static lunge and single-leg drop landing - a comparative study among three different toe directions. Journal of Experimental Orthopaedics, 6(1), 42. https://doi.org/10.1186/s40634-0190208-2

Hewett, T. E., \& Myer, G. D. (2011). The mechanistic connection between the trunk, hip, knee, and anterior cruciate ligament injury. Exercise and Sport Sciences Reviews, 39(4), 161-166. https://doi.org/10.1097/JES.0b013e3182297439

Hewett, T. E., Myer, G. D., Ford, K. R., Heidt, R. S., Jr., Colosimo, A. J., McLean, S. G., . . Succop, P. (2005). Biomechanical measures of neuromuscular control and valgus loading of the knee predict anterior cruciate ligament injury risk in female athletes: a prospective study. American Journal of Sports Medicine, 33(4), 492-501. https://doi.org/10.1177/0363546504269591

Hewett, T. E., Torg, J. S., \& Boden, B. P. (2009). Video analysis of trunk and knee motion during non-contact anterior cruciate ligament injury in female athletes: lateral trunk and knee abduction motion are combined components of the injury mechanism. British Journal of Sports Medicine, 43(6), 417-422. https://doi.org/10.1136/bjsm.2009.059162

Hughes, G., \& Dai, B. (2021). The influence of decision making and divided attention on lower limb biomechanics associated with anterior cruciate ligament injury: a narrative review. Sports Biomechanics, 1-16. https://doi.org/10.1080/14763141.2021.1898671

Kadaba, M. P., Ramakrishnan, H. K., \& Wootten, M. E. (1990). Measurement of lower extremity kinematics during level walking. Journal of Orthopaedic Research, 8(3), 383-392. https://doi.org/10.1002/jor.1100080310

Koga, H., Nakamae, A., Shima, Y., Bahr, R., \& Krosshaug, T. (2018). Hip and Ankle Kinematics in Noncontact Anterior Cruciate Ligament Injury Situations: Video Analysis Using Model-Based Image Matching. American Journal of Sports Medicine, 46(2), 333-340. https://doi.org/10.1177/0363546517732750

Koga, H., Nakamae, A., Shima, Y., Iwasa, J., Myklebust, G., Engebretsen, L., . . . Krosshaug, T. (2010). Mechanisms for noncontact anterior cruciate ligament injuries: knee joint kinematics in 10 injury situations from female team handball and basketball. American Journal of Sports Medicine, 38(11), 22182225. https://doi.org/10.1177/0363546510373570

Krosshaug, T., Nakamae, A., Boden, B. P., Engebretsen, L., Smith, G., Slauterbeck, J. R., . . Bahr, R. (2007). Mechanisms of anterior cruciate ligament injury in basketball: video analysis of 39 cases. American Journal of Sports Medicine, 35(3), 359-367. https://doi.org/10.1177/0363546506293899

Leppanen, M., Pasanen, K., Kujala, U. M., Vasankari, T., Kannus, P., Ayramo, S., . . Parkkari, J. (2017). Stiff Landings Are Associated With Increased ACL Injury Risk in Young Female Basketball and Floorball Players. American Journal of Sports Medicine, 45(2), 386-393. https://doi.org/10.1177/0363546516665810

Morishige, M., McQueen, D. A., Chong, A., Ballard, G. P., \& Cooke, F. W. (2010). The influence of sequential debridement in total knee arthroplasty on the flexion axis of the knee using computer-aided navigation. Journal of Orthopaedic Research, 28(6), 767-772. https://doi.org/10.1002/jor.21060

Moritz, C. T., \& Farley, C. T. (2004). Passive dynamics change leg mechanics for an unexpected surface during human hopping. The Journal of Applied Physiology (1985), 97(4), 1313-1322. https://doi.org/10.1152/japplphysiol.00393.2004

Negrete, R. J., Schick, E. A., \& Cooper, J. P. (2007). Lower-limb dominance as a possible etiologic factor in noncontact anterior cruciate ligament tears. Journal of Strength and Conditioning Research, 21(1), 270-273. https://doi.org/10.1519/00124278-200702000-00048

Padua, D. A., DiStefano, L. J., Beutler, A. I., de la Motte, S. J., DiStefano, M. J., \& Marshall, S. W. (2015). The Landing Error Scoring System as a Screening Tool for an Anterior Cruciate Ligament InjuryPrevention Program in Elite-Youth Soccer Athletes. Journal of Athletic Training, 50(6), 589-595. https://doi.org/10.4085/1062-6050-50.1.10 
Pashler, H. (1994). Dual-task interference in simple tasks: data and theory. Psychological Bulletin, 116(2), 220244. https://doi.org/10.1037/0033-2909.116.2.220

Sakurai, A., Harato, K., Morishige, Y., Kobayashi, S., Niki, Y., \& Nagura, T. (2019a). Effects of Toe Direction on Biomechanics of Trunk, Pelvis, and Lower-Extremity During Single-Leg Drop Landing. The Journal of Sport Rehabilitation, 1-6. https://doi.org/10.1123/jsr.2019-0050

Sakurai, A., Harato, K., Morishige, Y., Kobayashi, S., Niki, Y., \& Nagura, T. (2019b). The effects of toe direction on three-dimensional knee kinematics during closed kinetic chain exercise in patients with anterior cruciate ligament deficient knee. The Asia-Pacific Journal of Sports Medicine, Arthroscopy, Rehabilitation and Technology, 18, 1-5. https://doi.org/10.1016/j.asmart.2019.07.002

Song, Y., Li, L., Hughes, G., \& Dai, B. (2021). Trunk motion and anterior cruciate ligament injuries: a narrative review of injury videos and controlled jump-landing and cutting tasks. Sports Biomechanics, 1-19. https://doi.org/10.1080/14763141.2021.1877337

\section{Corresponding author:}

\section{Kengo Harato, MD, PhD}

Department of Orthopaedic Surgery, Keio University School of Medicine, 35 Shinanomachi, Shinjuku-ku, Tokyo, 160-8582, Japan.

Phone: $+81-3-5363-3812$

Fax: +81-3-3353-6597

E-mail: harato@keio.jp 